\title{
Research on Identification and Measurement Methods of Influencing Factors of Investment in Operation and Maintenance
}

\author{
Ma Lin ${ }^{1}$, Tong Ruigang ${ }^{2}$, Ren Yan $^{3}$, Zhao Lei $^{3}$, Sun Xizhen ${ }^{2 *}$ \\ ${ }^{1}$ State Grid Corporation of China, Beijing, China. \\ ${ }^{2}$ State Grid Shandong Electric Power Company,Jinan, Shandong, China. \\ ${ }^{3}$ State Grid Economic and Technology Research Institute Co., Ltd., Beijing, China.
}

\begin{abstract}
Operation and maintenance investment is an important part of the capital expenditure of power grid enterprises. In recent years, affected by multiple profit-cutting factors such as the macroeconomic downturn, the slowdown in electricity growth, the implementation of transmission and distribution price reform requirements, the narrowing of electricity price space, and the state's phased reduction of electricity cost policies, the profitability of power grid companies has dropped significantly, and power grid investment. The capacity was significantly weakened, and the operating pressure was unprecedented. Identifying and measuring the influencing factors of power grid operation and maintenance investment is an important supporting role for enterprises to formulate scientific and reasonable investment strategies for power grid equipment operation and maintenance. Therefore, this paper first applies the fish-bone method, combined with the current status of equipment operation and maintenance management of power grid enterprises, and scientifically identifies the factors that affect the investment level of operation and maintenance; then, based on the grey correlation theory, analyzes the degree of influence of each influencing factor.
\end{abstract}

\section{Introduction}

The benefits of power grid companies mainly come from the stable and continuous operation of equipment, and are closely related to the cost control of equipment. With the continuous development of my country's power grid, the tasks of operation, maintenance and overhaul of power grid equipment are getting heavier. As an important means to ensure the safe and reliable operation of power grid equipment, O\&M and maintenance play an important role in improving the safety and reliability of power grid operation, extending the service life of equipment, and reducing equipment energy consumption. Carrying out the identification and measurement analysis of the influencing factors of power grid operation and maintenance investment has a good supporting role in supporting power grid enterprises to make scientific and reasonable capital investment decisions.

Literature [1] combined with the current status of power grid enterprise operation and maintenance investment management, starting from improving the efficiency of power grid operation, applied DEA theory to evaluate the performance of power grid operation and maintenance investment, and proposed a grid operation and maintenance management strategy on this basis. Literature [2] proposed a method for power grid enterprise operation and maintenance resource prediction based on the asset wall theory, gave the asset mapping model design principle and specific analysis process based on the asset wall theory, and analyzed the life selection method of the physical assets of the power grid enterprise. As well as investment and operation and maintenance strategy decision-making methods for the predicted results of the asset wall. Literature [3] combines the cash flow reduction and weakening of investment capacity faced by grid companies, and the situation that grid investment is controlled by the government. From the national policy level, it systematically analyzes the impact mechanism of power system reform on capital investment in the operation and maintenance phase, and here Based on this, an optimization strategy for investment in operation and maintenance was proposed. Literature [4] uses the theory and method of risk management to establish a risk assessment model. Through the organic combination of equipment risk and cost management, establishes the net income model of overhaul and realizes the evaluation of the effect of equipment overhaul.

At present, existing research focuses more on the effectiveness evaluation, risk assessment and improvement strategy research of operation and maintenance investment. There is a lack of relevant analysis of the factors affecting operation and maintenance investment, and it cannot be scientific and reasonable for the current operation and maintenance investment decision under lean control. Provide basic support. This paper uses fishbone diagram method and gray correlation analysis theory to scientifically identify

*Corresponding author's e-mail: 1182306191@ncepu.edu.cn 
and measure the factors that affect the investment in power grid operation and maintenance, which has certain guidance and reference significance for supporting grid companies to formulate differentiated operation and maintenance investment strategies.

\section{Analysis of factors affecting operation and maintenance investment based on fishbone diagram method}

\subsection{Basic principles of fishbone diagram}

The fishbone diagram was invented by Dr. Ishikawa Kain of Japan, so it is also called the Ishikawa diagram. The basic idea is to extract factors from the structure and process of the analyzed object, and then draw each factor into a clearly structured and organized graph according to the correlation between the factors. Because the graphics look like fish bones, they are vividly called fish bone diagrams. Fishbone diagram method is a qualitative research method, which is widely used in management, technical and economic analysis and other fields. In actual operation, factors are generally divided into three levels: large, medium, and small. The basic model is shown in Figure 1:

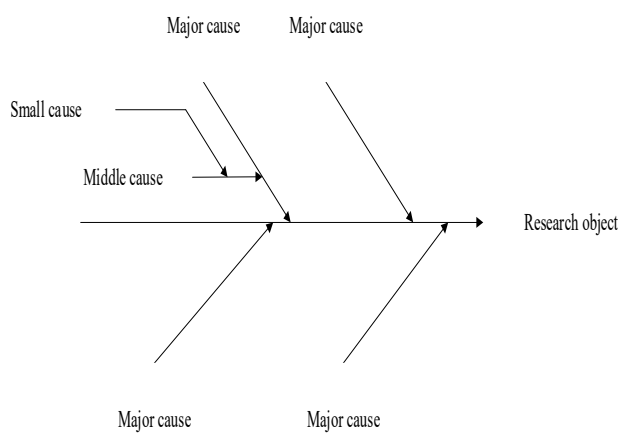

Figure 1. Fishbone diagram model.

Traditional fishbone diagrams have three types: problem fishbone diagrams, countermeasure fishbone diagrams, and cause fishbone diagrams. The problem-type fishbone diagram subdivides the researched problem into sub-problems and analyzes them one by one. At this time, the fishbone relationship is the structure of each problem rather than the causal relationship; the countermeasure fishbone diagram is listed in order to achieve a certain level. The countermeasures that can be taken by the purpose; while the cause-type fishbone diagram is to decompose a certain problem or phenomenon and find the cause from different aspects. The reason-type fishbone diagram is used in the analysis of factors affecting the cost of transmission and transformation projects.

\subsection{Implementation steps of fishbone diagram}

The application of fishbone diagram is divided into two steps, one is to analyze factors, and the other is to draw fishbone diagram. The specific implementation steps are shown in Figure 2 below.

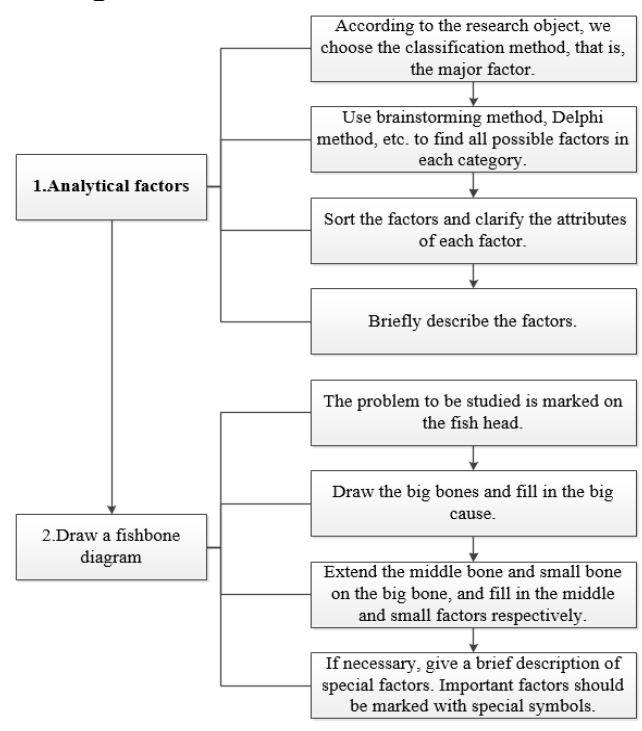

Figure 2. Fishbone diagram implementation steps.

\section{Research on the measurement of influencing factors of operation and maintenance investment based on gray correlation}

Gray correlation analysis is a method to measure the degree of correlation between various factors in the system. By comparing the development and change of various factors in the system, the gray correlation degree is used to quantitatively describe the strength of the relationship between the factors. Specific steps are as follows:

(1) Determine the analysis sequence. Let the dependent variable data constitute the reference sequence $X_{0}$, the respective variable data constitute the comparison sequence $X_{i}^{\prime}(i=1,2, \ldots, n)$, and the $n+1$ data sequences form the following matrix.

$$
\left(X_{0}{ }^{\prime}, X_{1}{ }^{\prime}, \ldots, X_{n}{ }^{\prime}\right)=\left[\begin{array}{cccc}
x_{0}{ }^{\prime}(1) & x_{1}{ }^{\prime}(1) & \ldots & x_{n}{ }^{\prime}(1) \\
x_{0}{ }^{\prime}(2) & x_{1}{ }^{\prime}(2) & \ldots & x_{n}{ }^{\prime}(2) \\
\ldots & \ldots & \ldots & \ldots \\
x_{n}{ }^{\prime}(N) & x_{n}{ }^{\prime}(N) & \ldots & x_{n}{ }^{\prime}(N)
\end{array}\right]
$$

Among

them:

$$
X_{i}^{\prime}=\left(x_{i}^{\prime}(1), x_{i}^{\prime}(2), \ldots, x_{i}^{\prime}(N)\right)^{T}
$$

$i=0,1,2, \ldots, n, \quad N$ is the length of the variable sequence.

(2) The commonly used non-dimensionalization methods for variable sequence are averaging method and initial value method.

$$
x_{i}(k)=\frac{x_{i}^{\prime}(k)}{\frac{1}{N} \sum_{k=1}^{N} x_{i}^{\prime}(k)}
$$

(3) Find the difference sequence, the maximum difference and the minimum difference to form the 
following absolute difference matrix. The largest and smallest numbers in the absolute difference matrix are the largest and smallest differences.

$$
\begin{gathered}
\Delta(\max )=\max { }_{1 \leq i \leq n}\left\{\Delta_{0 i}(k)\right\} \\
1 \leq k \leq N \\
\Delta(\min )=\min \left\{\Delta_{0 i}(k)\right\} \\
1 \leq i \leq n \\
1 \leq k \leq N
\end{gathered}
$$

(4) Calculate the correlation coefficient to transform the data in the absolute difference matrix as follows.

$$
\xi_{0 i}(k)=\frac{\Delta_{(\min )}+\rho \Delta_{(\max )}}{\Delta_{O i(k)}+\rho \Delta_{(\max )}}
$$

(5) Calculate the degree of relevance, compare the degree of relevance between sequence $X_{i}$ and reference sequence $X_{0}$ (reflected by $N$ correlation coefficients (reflected by the average, the degree of relevance between $X_{i}$ and $X_{0}$ can be obtained.).

$$
r_{0 i}=\frac{1}{N} \sum_{k=1}^{N} \xi_{0 i}(k)
$$

Sort the correlation degree between each comparison sequence and the reference sequence in descending order. The greater the correlation degree, the more consistent the changes of the comparison sequence and the reference sequence.

\section{Empirical analysis}

\subsection{Identification and analysis of influencing factors}

Based on the actual situation of power grid companies, this paper fully integrates the main influencing factors of asset operation and maintenance investment management, and identifies from different aspects such as market factors, operating factors, asset factors, and natural conditions factors. The introduction of fishbone diagrams to sort out the insuran factors of the distribution network asset operation and maintenance investment is shown in Figure 3.

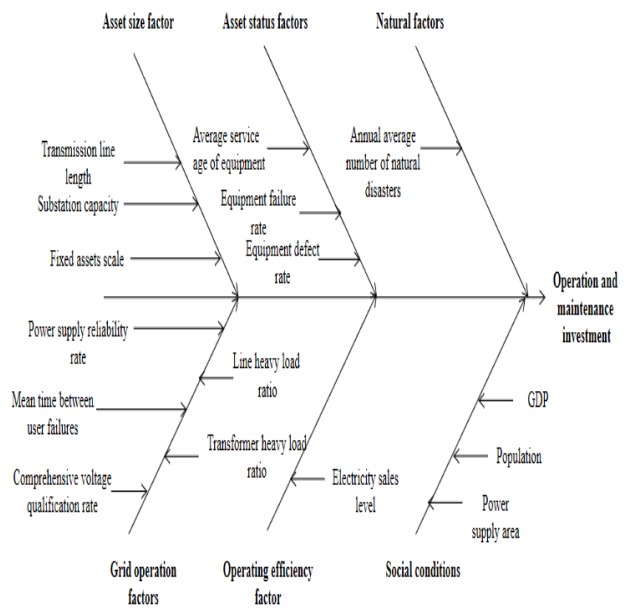

Figure 3.Analysis on Influencing Factors of Investment in Operation and Maintenance.

\subsection{Measurement and analysis of factors affecting operation and maintenance investment}

Relying on the results of clustering analysis and exploring the relationship of influencing factors based on the theory of gray correlation degree, as an important reference for the optimization of O\&M investment allocation, this paper selects 12 distribution grids in a certain area to carry out statistical analysis and

\begin{tabular}{|c|c|c|c|c|c|c|c|c|c|c|c|}
\hline Index & A & B & $\mathrm{C}$ & $\mathrm{D}$ & E & $\mathrm{F}$ & $\mathrm{H}$ & I & $\mathrm{J}$ & $\mathrm{K}$ & $\mathrm{L}$ \\
\hline Fixed assets scale & 0.18 & 0.26 & 0.20 & 0.17 & 0.24 & 0.21 & 0.39 & 0.23 & 0.29 & 0.30 & 0.33 \\
\hline Route mileage & 66.50 & 98.48 & 80.15 & 63.21 & 92.01 & 85.95 & 186.32 & 88.82 & 114.59 & 118.98 & 128.01 \\
\hline Substation capacity & 20350.50 & 32151.00 & 23011.50 & 20952.00 & 29451.00 & 25171.50 & 45484.50 & 25117.50 & 32670.00 & 36423.00 & 42348.00 \\
\hline $\begin{array}{l}\text { Average service age of } \\
\text { equipment }\end{array}$ & 12.32 & 16.02 & 14.67 & 11.90 & 15.71 & 13.52 & 14.33 & 14.31 & 16.44 & 18.72 & 19.17 \\
\hline Equipment failure rate & 5.40 & 6.60 & 6.15 & 5.10 & 6.75 & 5.70 & 5.70 & 6.75 & 7.20 & 8.25 & 8.70 \\
\hline Equipment defect rate & 4.65 & 5.70 & 4.80 & 4.65 & 5.70 & 7.35 & 4.65 & 6.30 & 6.75 & 6.45 & 6.30 \\
\hline $\begin{array}{l}\text { Power supply reliability } \\
\text { rate }\end{array}$ & 149.88 & 149.81 & 149.85 & 149.88 & 149.87 & 149.84 & 149.82 & 149.84 & 149.81 & 149.84 & 149.82 \\
\hline $\begin{array}{l}\text { Mean time between user } \\
\text { failures }\end{array}$ & 0.18 & 0.23 & 0.21 & 0.17 & 0.20 & 0.18 & 0.17 & 0.20 & 0.23 & 0.27 & 0.26 \\
\hline $\begin{array}{l}\text { Comprehensive voltage } \\
\text { qualification rate }\end{array}$ & 1.29 & 1.34 & 1.26 & 1.37 & 1.14 & 1.17 & 1.28 & 1.29 & 1.22 & 1.28 & 1.25 \\
\hline Line heavy load ratio & 14.30 & 18.35 & 8.15 & 7.41 & 6.78 & 6.71 & 5.10 & 17.72 & 6.35 & 19.01 & 8.01 \\
\hline $\begin{array}{l}\text { Transformer heavy load } \\
\text { ratio }\end{array}$ & 6.81 & 10.14 & 4.65 & 4.73 & 7.98 & 7.80 & 4.35 & 10.37 & 8.61 & 8.36 & 6.32 \\
\hline Electricity sales level & 485.30 & 731.67 & 518.21 & 574.29 & 617.82 & 662.70 & 1054.85 & 589.13 & 846.50 & 669.51 & 768.51 \\
\hline $\begin{array}{l}\text { Annual average number } \\
\text { of natural disasters }\end{array}$ & 21.00 & 18.00 & 15.00 & 7.50 & 9.00 & 13.50 & 10.50 & 12.00 & 13.50 & 16.50 & 12.00 \\
\hline
\end{tabular}
correlation calculation of related data. This paper selects 10 distribution grids in a certain area to carry out statistical analysis of related data and calculation of correlation degree. Some basic data of indicators are shown in Table 1.

Table 1. Basic data table. 


\begin{tabular}{cccccccccccccc} 
GDP & 15.35 & 23.01 & 13.70 & 13.44 & 19.29 & 22.14 & 39.23 & 23.87 & 22.01 & 20.97 & 22.14 & \\
Population & 2.46 & 3.20 & 2.42 & 2.63 & 2.69 & 2.51 & 4.10 & 2.75 & 2.64 & 4.29 & 3.27 & \\
Power supply area & 69.87 & 96.35 & 81.35 & 96.81 & 74.46 & 97.29 & 116.82 & 87.74 & 97.53 & 114.33 & 138.53 \\
$\begin{array}{c}\text { Operation and } \\
\text { maintenance investment }\end{array}$ & 302.27 & 384.00 & 351.26 & 284.06 & 423.65 & 319.38 & 586.07 & 375.84 & 427.05 & 486.35 & 475.85 \\
\hline
\end{tabular}

Combined with the characteristics of the data, the operation and maintenance investment and its influencing factors have the characteristics of different dimensions. When the gray correlation analysis is performed, the dimensionless processing is first required. Here, the standardized method is used to adjust each sequence. First set the resolution coefficient $r$, and then calculate the gray correlation degree between the distribution network operation and maintenance input sequence and the sequence of each influencing factor. Among them, the resolution coefficient $r=0.5$. The calculation results are shown in Table 2.

Tab 2. Results of grey correlation analysis.

\begin{tabular}{|c|c|c|}
\hline Category & Influencing factors & Grey correlation \\
\hline \multirow{3}{*}{ Asset size factor } & Fixed assets scale & 0.90 \\
\hline & Route mileage & 0.90 \\
\hline & Substation capacity & 0.87 \\
\hline \multirow{3}{*}{ Asset status factors } & $\begin{array}{l}\text { Average service age of } \\
\text { equipment }\end{array}$ & 0.82 \\
\hline & Equipment failure rate & 0.83 \\
\hline & Equipment defect rate & 0.77 \\
\hline \multirow{5}{*}{$\begin{array}{l}\text { Grid operation } \\
\text { factors }\end{array}$} & Power supply reliability rate & 0.58 \\
\hline & $\begin{array}{l}\text { Mean time between user } \\
\text { failures }\end{array}$ & 0.73 \\
\hline & $\begin{array}{l}\text { Comprehensive voltage } \\
\text { qualification rate }\end{array}$ & 0.77 \\
\hline & Line heavy load ratio & 0.64 \\
\hline & Transformer heavy load ratio & 0.65 \\
\hline $\begin{array}{l}\text { Operating efficiency } \\
\text { factors }\end{array}$ & Electricity sales level & 0.77 \\
\hline Natural factors & $\begin{array}{c}\text { Annual average number of } \\
\text { natural disasters }\end{array}$ & 0.68 \\
\hline \multirow{3}{*}{ Social conditions } & GDP & 0.75 \\
\hline & Population & 0.79 \\
\hline & Power supply area & 0.76 \\
\hline
\end{tabular}

It can be seen from Table 2 that the main factors affecting the investment level of power grid operation and maintenance are asset scale factors and asset status factors.

\section{Conclusion}

Increasing the lean level of investment in operation, maintenance and repair plays an important role in improving the safety level of equipment operation and operating efficiency of power grid enterprises. Based on the fishbone diagram theory, this paper reasonably identifies the factors that affect the investment in operation and maintenance, and uses the gray correlation degree to analyze the degree of influence of each factor, and provides technical guidance for the power grid enterprises to formulate scientific and reasonable investment strategies for operation and maintenance.

\section{Acknowledgments}

This research was supported by the Headquarters Technology Project (1400-202056414A-0-0-00) of the State Grid Corporation of China.

\section{References}

1. Lu Xiaofen, Yang Xiaoyong. Thinking about optimization of operation and maintenance investment in power grid enterprises[J]. Enterprise Management, 2017(S1): 232-233.

2. Luo Yu. Research on resource prediction of power grid enterprise asset operation and maintenance based on asset wall[D]. South China University of Technology, 2019.

3. Xu Jialong, Yu Min. Recommendations for fund investment management in the operation and maintenance phase of power grid equipment suitable for power system reform $[\mathrm{J}]$. Enterprise Management, 2016(S1): 90-91.

4. Liu Xiaomei. Research on the optimization of material cost of power grid enterprises based on risk analysis[D]. Northeast Dianli University, 2018.

5. Sun Wenkai. Research on Asset Life Cycle Cost Management [D]. North China Electric Power University, 2018. 